\title{
EL RECURSO DE PROTECCION Y SUS INNOVACIONES PROCESALES
}

\author{
Prof. Lautaro Ríos A. \\ Universidad de Valparaíso.
}

SUMARIO

1. QUE ES EL RECURSO DE PROTECCION (R. DE P.). 1.1: Definición. 1.2: Trascendencia. 1.3: Entorno Iberoamericano. 2. CARACTERIZACION DEL R. DE P. 2.1: Puesta en valor de determinados derechos, 2.2. Rango constitucional. 2.3: Méritos Procesales. 2.3.1. Informalidad. 2.3.2: Inquisitoriedad. 2.3.3: Unilateralidad. 2.3.4: Brevedad y concentración. 2.3.5: Amplitud. 2.3.6: Provisionalidad. 3. INNOVACIONES PROCESALES. 3.1.: Habilitación constitucional del A.C. № 3. 3.2: Virtual Inconstitu= cionalidad del A.A. de 1992. 3.3. Legitimación del A.A.-92. 3.4: Innovaciones relevantes. 3.6.1: Cómputo del plazo. 3.6.2: Admisibilidad del recurso. 3.6.3: Agregación a la tabla. 3.6.4.: Orden de no innovar. 3.6.5: El recurrido como "parte". 3.6.6: Plazo para fallar. e.6.7: Plazo para apelar. 1.6.8: Tramitación en 2a instancia. 3.6.9: Condena en costas. 4. LAS REFORMAS PENDIENTES. 4.1: Reformas constitucionales. 4.2: Reformas procesales. 4.3: Reforma de la competencia relativa. 5. CONCLUSIONES.

\section{QUE ES EL RECURSO DE PROTECCION (R. DE P.)}

1.1. Podemos definir el R. de P. como una acción procesal instaurada por la Constitución, cuyo carácter informal y sumarísimo permite al afectado por actos u omisiones arbitrarios o ilegales - que le agravien en el legítimo ejercicio de cualquiera de los derechos que la Carta especifica - para recurrir directamente a la Corte de Apelaciones respectiva, la cual queda habilitada para decretar las medidas que estime necesarias para restablecer el imperio del derecho y para asegurar la debida protección del agraviado.

1.2. Con todo, cualquiera definición - por completa que sea - no alcanza a describir el formidable aporte que el $R$. de $P$. ha venido a representar en el resguardo judicial de los derechos fundamentales o - lo que viene a ser lo mismo el inexplicable vacío que ha logrado subsanar en ese campo.

En efecto, antes de crearse esta acción especial, sólo existía su equivalente, el recurso de amparo o Habeas Corpus, pero referido solamente al derecho de libertad personal. De tal manera que la defensa de bienes jurídicos de tanta trascendencia como la vida, la honra o la inviolabilidad del hogar - por citar algunos - quedaba 
entregada a las vías procesales ordinarias o especiales, casi siempre demasiado lentas o insuficientes para otorgar un resguardo enérgico y oportuno al derecho conculcado, dirigido a suprimir el agravio y a restablecer prontamente su ejercicio legítimo.

1.3. La necesidad de proveer un remedio rápido y eficaz a los derechos individuales, en casos de abusos flagrantes o inminentes, ha germinado con mayor extensión y originalidad en el suelo americano que en el europeo.

En el entorno iberoamericano destaca, por su larga trayectoria, el amparo mexicano, instaurado en el Acta de Reforma de 1847 a la Constitución de 1824 (1). Este recurso - - que abarca tantas y tan complejas materias procesales, que es objeto de una cátedra especial - se concede "por leyes o actos de la autoridad que violen las garantías individuales"; y se resuelve por sentencia que sólo puede proteger a los individuos particulares o personas morales que lo hubieren solicitado, si procediere, " sin hacer una declaración general respecto de la ley o el acto que lo motivare".

También posee perspectiva histórica el "mandato de segurança" - o mandanto de seguridad - brasileño, proveniente de la Carta de 1880, que estúvo originalmente confundido con el habeas corpus en una disposición que concedía el recurso a toda persona "que sufra o se halle en inminente peligro de sufrir violencia o coacción por ilegalidad o abuso de poder". A partir de la Carta de 1946, ambos institutos fueron separados y así coexisten en la actual Constitución de Brasil de 1988, que lo concede "para proteger un derecho neto y cierto, no amparado por el 'habeas corpus' o el 'habeas data', cuando el responsable de la ilegalidad o abuso de poder fuere autoridad pública o agente de una persona jurídica en ejercicio de atribuciones de Poder Público"(2).

Especial referencia merece el amparo argentino, tanto por su gestación como por su contenido. En efecto, el amparo argentino (3) es obra de la jurisprudencia de los tribunales, siendo su mérito adicional el hecho de carecer de fundamento expreso en la Constitución de 1853. Su origen proviene de la posición innovadora sustentada por la Corte Suprema de Justicia en los casos Angel SIRI (1957) y Samuel KOT S.R.L. (1958). En este último caso la Corte - al decir del Prof.Nélson SAGUES (4) - sintetizó magistralmente su doctrina en el siguiente texto: siempre que aparezca, en consecuencia, de modo claro y manifiesto, la ilegitimidad de una restricción cualquiera a alguno de los derechos esenciales de las personas, así como el daño grave e irreparable que se causaría remitiendo el examen de la cuestión a los procedimientos ordinarios, administrativos o judiciales, corresponderá que los jueces restablezcan de inmediato el derecho restringido, por la rápida vía del recurso de amparo".

Expandida esta doctrina jurisprudencial que había contado con el resuelto apoyo de la cátedra, ella fue plasmada en la ley Federal № 16.968 del año 1966 , cuyo art. $1^{2}$ prescribe que "La acción de amparo será admisible contra todo acto u omisión de autoridad pública que, en forma actual o inminente, lesione, restrinja, altere o amenace con 
arbitrariedad o ilegalidad manifiesta, los derechos o garantías explícitas o implícitamente reconocidos por la Constitución Nacional, con excepción de la libertad individual tutelada por el habeas corpus" (5).

Puede advertirse un notorio parentesco o - al menos - una idéntica fisonomía entre nuestro recurso de protección y el amparo argentino emergente en la jurisprudencia judicial de ese país a partir de 1957 y legislado con una década de anterioridad al nuestro (6).

\section{CARACTERIZACION DEL R. DE P.}

Si hubiera que caracterizar el R. de P. en nuestro ordenamiento jurídico, habría que especificar los distintos planos en que se revela su extraordinaria valía.

2.1. Puesta en valor determinados derechos.- El vigor jurídico de los derechos públicos subjetivos no radica tanto en su declaración en la Carta Fundamental ni en las garantías que resguardan su cabal ejercicio, sino principalmente en la tutela que ante cualquier agravio - así sea en grado de amenaza - pueda recabarse de los tribunales de justicia, guardianes naturales de tales derechos.

El recurso de protección constituye lá tutela judicial por excelencia de cada uno de los derechos fundamentales protegidos.

2.2. Rango constitucional.- El R. de P. se inscribe entre las escasas acciones procesales instituidas directamente por la Constitución Política; y, por ello, está dotado de la supremacía normativa, de la estabilidad y de la aplicación preferente, que son cualidades propias de la Carta Fundamental. Además, el R. de P. dispone de una estructura procedimental, diseñada en el art. 20 de la Constitución que incluye sus efectos.

2.3. Méritos procesales.- En agudo contraste con los lentos rituales e interminables procedimientos ordinarios - y también, a veces, con procedimientos sumarios que tardan años en afinarse - el $\mathrm{R}$. de $\mathrm{P}$. tiene un procedimiento informal, inquisitivo, unilateral, breve y concentrado, abierto y provisorio.

2.3.1. Informalidad - Sin llegar a ser oral, el R. de P. puede redactarse en papel simple, o en una acta levantada en la Secretaría del Tribunal y, aún, puede interponerse a distancia, por telégrafo o por telex. Puede presentarse por el afectado o por otro a su nombre, sin requerir éste poder de aquél; no necesita patrocinio de abogado ni intervención de procurador (7). Resulta difícil concebir mayor informalidad en el ejercicio de una acción de tanta importancia.

2.3.2. Carácter inquisitorio.- En lo tocante a la prueba, y aun cuando el procedimiento no contempla una fase ni un período probatorio, su carácter inquisitivo se refleja en el deber del tribunal de primera instancia de indagar los actos u omisiones de- 
nunciados, su talante arbitrario o ilegal y el agravio que ellos puedan haber producido al legítimo ejercicio del derecho invocado por el recurrente. Esta información, así como todos aquéllos antecedentes que digan relación con el asunto, son requeridos por el tribunal ordenando que la persona o entidad a quien se atribuye al acto u omisión agraviante, remita a la Corte el informe y los antecedentes referidos dentro del plazo breve y perentorio que se le señale.

De esta manera, el recurrente tiene oportunidad de probar su derecho, así como el acto u omisión agraviante y su origen, al presentar su recurso y hasta antes de la vista de la causa; y aquél de cuyo obrar se pide protección, lo tiene al emitir su informe y también hasta antes de dicha vista.

La E. Corte Suprema, en cambio, oficiando como tribunal de segunda instancia, tiene la facultad indagatoria - sea para entrar al conocimiento de la apelación, o bien, para mejor acierto del fallo - de poder solicitar, a cualquiera persona o autoridad, los antecedentes que considere necesarios para tales efectos (8).

Acerca del grado de convicción que el tribunal pueda adquirir en esta fase inquisitiva, es oportuno señalar que el mérito probatorio de todos los antecedentes y pruebas que se alleguen o el resultado de las diligencias y trámites que se produzcan, será apreciado en conciencia por el tribunal (9).

Lo cual quiere decir que éste queda liberado de la fuerza vinculante de las normas que regulan el valor comparativo de los medios de prueba; pero no lo queda de su obligación de justicia con criterio libre, pero racional - es decir, en forma convincente los hechos y las circunstancias que le servirán de base para estimar o rechazar el Recurso, no bastando para ello la consabida frase ritual ... "que apreciando en conciencia las pruebas producidas, el tribunal da por establecido ... etc." (10).

2.3.3. Unilateralidad.- Debe señalarse. como carácter particularísimo del R. de P., su unilateralidad. EI R. de P. existe para establecer el imperio del derecho y dar al agraviado la protección debida. Lo cual no requiere la existencia ni la presencia de contraparte, ya que ninguna prestación se pide contra nadie (11).

El procedimiento del R. de P. es unilateral, porque está establecido en beneficio del titular de esta acción y en resguardo de sus derechos sin otra consideración, respecto del agresor, que requerir su informe, como un tercero ajeno al proceso.

Naturalmente, lo anterior no obsta a que el responsable del acto u omisión agraviante - respecto del cual se solicitarán ordinariamente medidas protectoras - se haga parte en el recurso y pueda ejercer, desde ese instante, los derechos procesales que incumben a quienes invisten tal carácter, tales como alegar, suspender la vista de la causa, o interponer recursos contra la sentencia definitiva (12). 
2.3.4. Procedimiento breve y concentrado.- Uno de los méritos más apreciables del R. de $\mathrm{P}$. consiste en estos caracteres de su procedimiento.

Este consta de tres frases en la primera instancia: la admisión del recurso, la inquisitiva y la de decisión.

Producido el acto u omisión agraviante de un derecho fundamental protegido, el agraviado dispone del plazo fatal de quince días corridos para ejercitar la acción que nos ocupa. Presentado el recurso, el tribunal examina si reúne los requisitos de admisibilidad - plazo, titularidad de la acción, existencia de un derecho protegido y de un acto u omisión agraviante- y, en caso afirmativo, inicia su tramitación, concluyendo así la primera fase (13).

La fase inquisitiva está destinada a la verificación de los requisitos de procedencia y de estimación del recurso. Su duración dependerá de la vía "más rápida y efectiva" que el tribunal elija para recabar el Informe y los antecedentes que debe proporcionarle el agraviante y del "plazo breve y perentorio" que le señale para remitirlos a la Corte. Esta puede prescindir del informe y de los antecedentes señalados si no los recibe en la oportunidad debida (14). Esta fase puede prolongarse por los medios: la disposición de trámites indispensables y previos a la vista de la causa y la dictación, antes del acuerdo. de medidas para el mejor acierto del fallo (15).

La fase de decisión, a partir del estado de acuerdo, es muy breve; tanto el tribunal de primera como el de segunda instancia disponen del plazo fatal de cinco días hábiles para fallar el R. de P. o la apelación, en su caso, desde que la causa se halle en estado. Este plazo se reduce a dos días cuando el Recurso ha recaído en el derecho a la vida y a la integridad de la persona, en la prohibición de ser juzgado por comisiones especiales, en la libertad de expresión o en el derecho de reunión (16).

El procedimiento en segunda instancia es aún más breve y concentrado, por la inexistencia de una fase inquisitiva y por el conocimiento ordinario del recurso "en cuenta preferente", que debe darse dentro de cinco días desde que sea ordenada, toda vez que la vista de la apelación ha pasado a ser excepcional (17).

Oportuno es recordar, por último, que siempre la vista del Recurso goza de tratamiento preferente, mediante su agregación extraordinaria a la tabla de la Sala que corresponda (18).

2.3.5. Amplitud del procedimiento del R. de P.- Con esta calificación queremos señalar que, a diferencia de los procedimientos contenciosos, en que la competencia y el espacio de movilidad del juez quedan acotados por las acciones y excepciones de las partes, por la calificación jurídica que ellas hacen de los hechos y hasta por las normas aplicables que invocan, en el R. de P. - supuestas su admisibilidad y procedencia - el único límite del juez está en su sujeción a las finalidades de esta ac- 
ción procesal que consisten - como ya hemos dicho - en restablecer el imperio del derecho (fin social) y asegurar al agraviado la protección debida (fin personal).

El tribunal puede adoptar todas y cualquiera clase de medidas tendientes a estos objetivos, aunque no parezcan establecidas en ningún código ni hayan sido solicitadas por el recurrente.

Este puede equivocar la calificación jurídica de los hechos u omisiones agraviantes, y el juez corregirla, siempre que éstos hayan sido acreditados debidamente. Puede errar en la individualización del derecho que cree lesionado y - por ende - en la cita de la disposición constitucional aplicable, y el juez enmendarlas, siempre que aparezca claramente comprometido un derecho constitucionalmente protegido del recurrente.

Estas conclusiones arrancan tanto del sentido y espíritu de los arts. $5^{\circ}$ inc. $2^{\circ}$ reformado y 20 de la Constitución Política, como de la finalidad esencialmente tutelar de los derechos fundamentales protegidos por este último precepto, encomendada con tan elevado rango normativo a los tribunales de justicia. Así también se manifiesta en abundante jurisprudencia.

2.3.6. Carácter provisorio de la sentencia (19).- No cabe duda que la resolución que decide un R. de P. tiene el carácter de una sentencia definitiva; no sólo por aplicación analógica de la definición que de éstas nos da el art. 158 inc 2 del Código del Procedimiento Civil, sino porque así lo declara expresamente el № 5 del Auto Acordado sobre la tramitación de este Recurso.

Sin embargo, el efecto de la cosa juzgada que emana de ella es sólo de naturaleza formal, en presencia de la parte final del primer inciso del art. 20 de la Carta, que previene que el R. de $P$. y. lo que la Corte decida a su respecto es "sin perjuicio de los demás derechos que (el agraviado) pueda hacer valer ante la autoridad o los tribunales correspondientes".

El efecto formal de la cosa juzgada impide que pueda deducirse un nuevo $R$. de $P$. si, con respecto al primero, existe la consabida triple identidad de persona, de cosa pedida y de causa de pedir (20).

Pero, precisamente por tratarse de un procedimiento de emergencia, carente de un período de prueba y de un principio contradictorio, en que se trata de proteger o restablecer el statu preexistente a la agresión que lo origina, impidiendo a un tiempo la autotutela jurídica y la violación flagrante o inminente de un derecho probado y protegido, la Constitución ha debido dejar a salvo el derecho de discutir el fondo de la cuestión que ha motivado el recurso, o su rechazo, en un juicio de lato conocimiento o por otra vía administrativa o jurisdiccional que sea procedente. 
En resumen, la sentencia firme en este proceso no produce cosa juzgada material o substancial, sino, simplemente, cosa juzgada formal; y así, puede concluirse que es provisoria, como toda solución de emergencia (21).

\section{INNOVACIONES PROCESALES INTRODUCIDAS AL PROCEDIMIENTO ORIGINAL}

3.1. Habilitación constitucional del A.C. Ne3.- Una vez establecida la naturaleza, los caracteres y el diseño breve y concentrado del procedimiento, estamos en situación de analizar las modificaciones introducidas en éste, por la Excma. Corte Suprema, mediante el Auto Acordado de 24 de Junio de 1992 (D.O. del 27-VI-92) que vino a reemplazar el anterior instrumento de regulación procedimental, esto es, el Auto Acordado del 29 de marzo de 1977.

No es ocioso recordar aquí que el Auto Acordado de marzo de 1977 - que estableció el procedimiento del R. de P. instituido en el art. $2^{\circ}$ del Acta Constitucional №3 de septiembre de 1976 - tuvo habilitación constitucional expresa referida al órgano al que se otorgó competencia para dictarlo, al instrumento normativo dictado y al encargo cometido.

El inciso segundo del mismo artículo prescribió: "La Corte Suprema dictará un auto acordado que regule la tramitación de este recurso".

Con todo - y, no obstante, tan clara habilitación de rango constitucional - se criticó en su momento a la Excma. Corte por haberse excedido en su cometido al limitar el ejercicio de esta acción imponiéndole un plazo breve de prescripción extintiva - o de caducidad - de quince días corridos, y estableciendo eventuales sanciones administrativas que aun podrían recaer en funcionarios de la Administración del Estado no dependientes de la línea jerárquica de los tribunales de justicia; todo lo cual - y sin perjuicio de otros reparos de menor importancia - excedía notoriamente el encargo de reglas la tramitación del recurso (22).

3.2. Virtual inconstitucionalidad del A.A. de 1992.- La cuestión fundamental que se suscita consiste en dilucidar si pudo la Excma. Corte sustituir un Auto Acordado para cuya dictación tuvo expresa competencia por otro con respecto al cual:

a) se agotó, con su ejercicio, la habilitación que tuvo respecto del primero;

b) el órgano constituyente que le otorgó competencia se encuentra disuelto;

c) el Acta Constitucional habilitante de la potestad ejercida por la E. Corte fue orgánicamente derogada y sustituida por la Constitución de 1980, que nada dice al respecto; 
d) la regulación procesal de una acción de rango constitucional, referida al ejercicio de derechos fundamentales y sus garantías, es materia legislativa; y aún más, es materia de competencia exclusiva del Congreso Nacional, que a éste le está vedado delegar en el Ejecutivo (art. 61 inc. 2 - C.Pol.);

e) las facultades económicas invocadas por la E. Corte para dictar el Auto Acordado del 24-VI-92 no confiere un poder normativo vinculante de carácter general, lo que es propio de la ley; ellas son, en cambio, facultades para regular el régimen interno de los tribunales de justicia y las materias administrativas propias de su organización y funcionamiento, mediante reglas que, por emanar del poder jerárquico del órgano que las dicta, sólo obligan a quienes le están subordinados en la escala gradual respectiva;

f) El Auto acordado referido, no obstante, su contenido legislativo y su trascendencia constitucional, sobrepasa el sistema normativo vigente al escapar a todo control de constitucionalidad (22-bis);

g) se añade, por último, que por idénticas razones a las esgrimidas contra el Auto Acordado de 1977, sumadas a las seis que anteceden, tanto el plazo de extinción del Recurso como las sanciones administrativas que contiene el № 15 del Auto Acordado de 1992, excederían el marco de las atribuciones de la Excma. Corte; tanto más si se considera - respecto de la limitación del plazo extintivo - que ni el propio legislador podría imponerla, en presencia de la garantía general del №26 del art. 19 de la C. Pol.; tanto, porque dicha limitación no está autorizada por la Constitución, cuanto, porque los preceptos legales que regulen las garantías que ésta establece no podrán imponer requisitos (el plazo) que impidan su libre ejercicio.

3.3. Legitimación del Auto Acordado de 1992.- con todo, y sin perjuicio de dejar estampadas las inquietudes que, en torno a tan interesante materia, han provocado el debate académico, no nos detendremos en ellas por las razones que pasamos a expresar:

3.3.1. Paradojalmente, no existe en Chile un cuerpo normativo más ilegítimo en su origen que la Constitución que nos rige (23). Y, sin embargo, la Constitución del 80 se ha ido legitimando por su creciente aplicación en la vida nacional y su generalizado acatamiento por la ciudadanía, los partidos políticos y los operadores jurídicos. La inconstitucionalidad teórica del Auto Acordado de 1992 decae frente a la legitimación que le otorga su aplicación diaria y su universal acatamiento, amén de sus innegables ventajas procesales sobre el A.A. de 1977.

3.3.2. Si hubiera que indagar por el órgano idóneo para resolver la pretensión de inconstitucionalidad del Auto Acordado de 1992, descubriríamos que se trata del mismo tribunal que lo dictó; de manera que estaríamos frente a una pretensión sin sentido, con la agravante que el recurso de inaplicabilidad no se concede en con- 
tra de Autos Acordados de los Tribunales Superiores, porque las normas de estos instrumentos no son preceptos legales.

3.3.3. Nos ha parecido necesario hacer constar las reservas que se han formulado en los medios académicos, y que compartimos, a la constitucionalidad del Auto Acordado de 1992 porque creemos que ese testimonio no debe silenciarse al momento de hacer el análisis de las ventajas comparativas de este Auto Acordado, con respecto al original, no obstante, su inconstitucionalidad. Prevenido lo cual entramos directamente en materia.

3.4. Motivación de A.A. de 1992.- Los motivos que impulsaron a la E. Corte para aprobar, de oficio, la modificación del procedimiento original de R. de P., fueron exteriorizados en los fundamentos del Auto Acordado de 1992, y son:

3.4.1 La evidencia de que el $R$. de $P$., en los tres lustros transcurridos desde su entrada en vigencia, "se ha consolidado como acción jurídica de real eficiencia para la necesaria y adecuada protección jurisdiccional de los derechos y garantías individuales sujetos a la tutela de este medio de protección constitucional"; y

3.4.2. La constatación de un uso "cada vez más creciente del mismo y, por ende, un progresivo aumento del volumen de ingreso de estos recursos en las Cortes de Apelaciones del país y, por consiguiente, también de esta Corte Suprema por la vía de la apelación de la sentencia recaída en estas causas".

3.5. Finalidades perseguidas.- También se expresa allí los objetivos que se persiguen con tales modificaciones, a saber:

3.5.1. "obtener una mayor expedición en su tramitación y despacho final".

3.5.2. "conferir a los agraviados mayor amplitud y facilidad para la defensa de las garantías constitucionales que les fueron conculcadas";

3.5.3 "simplificar la tramitación del recurso de apelación... de manera que esta Corte pueda conocer y resolver con mayor prontitud dicho recursos"; y

3.5.4. evitar que el alto ingreso de apelaciones en los R. de P. agregadas a las otras materias que también deben figurar extraordinariamente en las tablas de las diversas Salas de la E. Corte, retrase su Conocimiento y fallo, así como la postergación de los demás recursos y causas de la tabla ordinaria (24).

3.6. Innovaciones relevantes.- De los factores motivantes y de las finalidades perseguidas para modificar el procedimiento, cabía esperar reformas más substanciales; las cuales confiamos en que, en un futuro cercano, sean abordadas por el legislador con el concurso de las Universidades y de los propios Tribunales de Justicia. 
con todo, las innovaciones introducidas tienen el mérito destacable de ser, alguna de ellas, el resultado de la jurisprudencia de los tribunales superiores, y todas, soluciones prácticas que mejoran y agilizan el procedimiento.

Por otra parte, son dignas de apreciar una ordenación más lógica de la secuencia de las normas en relación con la estructura del procedimiento, así como la redacción clara y explícita de sus preceptos.

Nos referimos, a continuación, en el orden en que ellas aparecen en los ordinales del Auto Acordado, a las innovaciones que nos parecen más relevantes.

3.6.1. Forma de computar el plazo del recurso.- Bajo el texto anterior, el plazo de 15 días corridos para interponer el recurso, se contaba secamente desde la fecha en que se había "cometido el acto" o "incurrido en la omisión" que motiva el recurso.

Alguna jurisprudencia llegó a ser drásticamente restrictiva. En los casos de actos continuados o reiterados, consideró el primero de ellos para el cómputo del plazo, aun cuando hubiera evidencia que la acción injustamente perjudicial continuaba vigente al interponerse el recurso (25). En la situación de violación de derechos provenientes de la aplicación de un acto administrativo dictado con anterioridad a las actuaciones lesivas, a veces se tomó en consideración la fecha de emisión de tal acto, sin entrar a considerar la falta de conocimiento o de comunicación del mismo al agraviado (26).

La materia adquiría especial importancia en el caso de actos administrativos que no se notifican a los terceros posteriormente agraviados por sus efectos materiales $y$, aún más, cuando tales efectos lesivos no pueden advertirse inicialmente, como ocurre frecuentemente en la construcción de obras amparadas en los correspondientes permisos de edificación, que adolecen de infracción a las normas urbanísticas o producen a los vecinos perjuicios que se manifiestan mucho después de extinguido el plazo, si éste se cuenta desde la fecha del permiso.

Así pues, la jurisprudencia fue evolucionado progresivamente sea exigiendo la comunicación efectiva del acto lesivo, como requisito previo para iniciar el cómputo del plazo del recurrente afectado por el mismo (27); sea formulando la teoría del "conocimiento cierto de los hechos" como presupuesto para la iniciación del plazo para presentar el recurso; teoría cuya bondad consiste en permitir que el R. de P. cumpla su finalidad garantista, evitándo en esta forma la frustración injusta del agraviado (28).

La bondad de esta teoría - así como su extensión jurisprudencial a numerosas situaciones similares - indujo probablemente a la Excma. Corte a modificar el № 1 del A.A. de 1977, cuyo correspondiente en el A.A. de 1992, señala que deberá interponerse "dentro del plazo fatal de quince días corridos contados desde la ejecución del acto o la ocurrencia de la omisión, O, SEGUN LA NATURALEZA DE ESTOS, DESDE QUE SE 
HAYA TENIDO NOTICIAS O CONOCIMIENTO CIERTO DE LOS MISMOS, lo que se hará constar en autos"

Ciertamente, el nuevo texto transcrito disminuye la drástica consecuencia extintiva del breve plazo concedido para la interposición del Recurso, cuando el acto o la omisión motivante no ha llegado de inmediato al conocimiento del afectado; y alienta, a este respecto, la interpretación proclive a la admisibilidad del recurso.

3.6.2. Examen de admisibilidad del recurso.- La nueva redacción del encabezamiento del № 3 del Auto Acordado vigente, induce a pensar que contempla, como un trámite necesario y previo - a cargo del Presidente de la Corte de Apelaciones respectiva o de la Sala Tramitadora, si existen varias Salas - el examen de admisibilidad.

En efecto, mientras el texto anterior decía "INTERPUESTO el recurso el Tribunal pedirá informe... etc.", el actual prescribe: "ACOGIDO A TRAMITACION el recurso, la Corte de Apelaciones ordenará ... etc." (29).

"Acoger a tramitación" un asunto implica una decisión asertiva de que los requisitos de admisibilidad del Recurso, antes de hacer progresar su tramitación, es recomendable para evitar una actividad procesal fatigosa e inútil que sólo venga a advertirse como tal al momento de fallar el recurso.

Los requisitos de admisibilidad del $\mathrm{R}$. de $\mathrm{P}$. son : a) la constatación aparente de hallarse, quien recurre, dentro del plazo establecido; b) la titularidad del recurrente - o de aquel a cuyo nombre se interpone el recurso - de un derecho o garantía constitucional expresamente protegido en el art. 20 de la C. Política; c) el hecho de aparecer afectado el derecho o garantía cuya protección se invoca, por un acto u omisión que se pretenda ilícito, esto es, arbitrario o ilegal, o de ambas especies en el caso del art. 19 № 8 de la C. Pol.; y d) que dicho acto u omisión aparezca agraviante para el afectado, esto es, tenga la virtualidad de privarle, perturbarle o amenazarle en el legítimo ejercicio de su derecho.

Naturalmente, si faltare alguno de estos cuatro requisitos, el Recurso debiera declararse inadmisible y - por ende - negarse curso a su tramitación.

3.6.3. Agregación del Recurso en la tabla del día subsiguiente.- Aunque parezca un detalle irrelevante haber cambiado la agregación extraordinaria de la causa en la tabla del día siguiente (A.A. de 1977) por el día subsiguiente al de recepción del lnforme (A.A. en actual vigencia) este detalle permite al recurrente disponer de un plazo prudencial para hacerse cargo del examen de la documentación - a veces profusa - que remita a la Corte el recurrido y de los argumentos que éste invoque en su Informe de rigor.

En la situación anterior, el recurrente disponía sólo de horas para examinar los antecedentes y la oposición al recurso que debía rebatir al día siguiente, en cir- 
cunstancias que - a menudo, en los caso complejos - el recurrido había solicitado y obtenido la ampliación generosa del plazo concedido por la Corte para informar.

La modificación señalada, sin ir en desmedro de la brevedad del proceso, permite una posición más desahogada del titular del recurso para defender su derecho.

3.6.4. Orden de no innovar.- Esta importante innovación, que no figuraba en el A.A. de 1977, rinde pleitesía al afán literalista de un buen número de nuestros jueces.

En innumerables casos, $y$, no obstante, su necesidad imperiosa para la suerte del recurso, los tribunales se resistieron a decretar esta medida, u otras de similar efecto, por la simple razón de que ellas no estaban expresamente consultadas en dicha regulación. Como argumento concluyente de la improcedencia de la orden de no innovar en el $R$. de P., alegaban que un tribunal sólo tiene las facultades que expresamente se le conceden; y que, además no se podía dar igual trato al titular de un recurso que contemplara dicha garantía procesal, que al titular de otro en que ella estaba ausente.

No parecían advertir estos jueces que la habilitación para disponer cualquiera medida cautelar del resultado del R. de P. está contenida en el propio art. 20 de la $C$. Pol., normal infinitamente más amplia y de mayor rango que el Auto Acordado de 1977.

En efecto, es dicho artículo 20 el que autoriza y ordena a la Corte de Apelaciones adoptar de inmediato las provinencias que juzgue necesarias para restablecer el imperio del derecho y asegurar la debida protección al afectado.

"De inmediato" quiere decir "que suceda de seguida, sin tardanza" (R. Acad.); también significa "sin mediatez", en este caso, de sentencia ni de ningún otro trámite. "Las provinencias que juzgue necesarias" significa cualquier clase de provinencias; y si caben las definitivas, con mayor razón proceden las tutelares que tienen a posibilitar la eficacia de aquéllas y protección efectiva del agraviado.

Seguimos creyendo que la facultad atribuida al juez por el №3, cuarto párrafo, del A.A. de 1992, consiste en poder decretar orden de no innovar cuando lo juzgue conveniente para los fines del recurso, es menos amplia y omnicomprensiva que la que otorga, con supremo rango normatico, la propia Constitución.

Pero, en vista del criterio ceñido a la letra de las normas, que aún prevalece en muchos jueces y de la falta de fe en las facultades implícitas de toda magistratura, juzgamos positivamente la decisión de la Excma. Corte de aclarar la precedencia indudable de la orden de no innovar en la tramitación de este Recurso.

3.6.5. La condición de parte en el Recurso.- No es que en esta importancia material se hayan introducidos modificaciones substanciales: Pero la nueva regulación per- 
mite perfilar más nítidamente el rol eventual de "parte" del recurrido (30) y sus prerrogativas procesales.

Como ya señalamos, este procedimiento es unilateral y no requiere de contraparte; pero puede derivar en bilateral si las personas, funcionarios u Organos del Estado afectados por el Recurso - es decir, los "recurridos" - deciden "hacerse parte" en el mismo (31).

Carece de interés examinar la condición de "parte" del recurrente, porque ambos roles se confunden. No hay recurrente de protección que no sea parte en su propio recurso.

En cambio, sólo desde el momento que el recurrido se hace parte deja de ser tercero en el proceso y adquiere los derechos y cargas propios de esa condición. Veamos cuáles son éstos.

En primer lugar, sólo cuando el recurrido se hace parte tiene el derecho a suspender la vista de la causa, en las condiciones que para "la otra parte" especifica el № 9 del A.A.

En seguida, sólo "los recurridos que se hubieren hecho parte" en el recurso - y, el recurrente, por supuesto - serán notificados personalmente o por el estado diario de la sentencia definitiva.

Y como sólo las partes pueden deducir recursos y tales recursos tienen plazos a contar de la notificación de la resolución que los motiva, sólo el recurrido que se ha hecho parte - además del recurrente - puede apelar de la sentencia definitiva de primera instancia. Así se desprende de los principios generales del Derecho Procesal y del № 6 del A.A.

En cuarto lugar, sólo el recurrido - parte puede designar abogado para que alegue por él, tanto en primera como en segunda instancia, si se ordena traer el recurso en relación en esta última. Así se desprende del № 9 y del № 7 del A.A. cuando, respectivamente, se refiere a "la otra parte" y a "los abogados de las partes".

Nos ha parecido conveniente poner en relieve la diferente situación del recurrido cuando decide hacerse parte, porque, bajo la vigencia del A.A. de 1977 pudimos advertir, a veces, un trato indiferenciado entre ambos roles, permitiendo - por ejemplo - alegar el recurso o apelar de la sentencia al recurrido que no se había hecho parte (32).

3.6.6. Ampliación del plazo para emitir el fallo.- En el sistema anterior, el plazo fatal para fallar era distinto, según se tratara de "las garantías constitucionales" contempladas en los Nos. 1, 3 inc. 4, 7, 12 y 19 inc. final del art. 1² del Acta Constitucional № 3, o el recurso se refiriera a "las demás garantías" (33) señaladas en el art. $2^{a}$ del Acta, en el que fue instituido el Recurso de Protección. 
En la primera situación el plazo para fallar el recurso era de veinticuatro horas (!); en la segunda, era de tres días; ambos plazos-se contaban - al igual que en la reforma - desde que la causa estuviera en estado de dictar sentencia.

El A.A. de 1992 amplió, con prudencia y criterio práctico, estos plazos verdaderamente fatales para resolver tan delicadas materias; las que, a veces, para mayor dificultad, se embrollan en gruesos expedientes. Eliminó, además, del listado de suma urgencia, el derecho a la libre iniciativa particular en la ejecución de acciones de salud, inscrito en el derecho a la salud, en que la actual Constitución protege con el recurso, el derecho de cada persona a elegir el sistema de salud - estatal o privado - al que desee acogerse (34).

Actualmente, el plazo para dictar sentencia en el $R$ de $P$., es de cinco días hábiles a contar desde la fecha en que la causa se halle en estado. Pero, tratándose del derecho a ser juzgado por el juez natural y no por comisiones especiales, de la libertad de expresión y del derecho de reunión, el fallo debe emitirse dentro del segundo día hábil desde que la causa quede en estado de sentencia; plazo breve - este último - pero no angustioso como el anterior, que resulta perfectamente justificable por la importancia de los derechos concernidos y la urgencia de otorgarle un amparo judicial oportuno.

3.6.7. Ampliación del plazo para apelar.- Una de las reformas más apreciables para las partes y para los fines de $R$. de $P$. es la que se refiere al plazo del recurso de apelación de la sentencia definitiva de primer grado, "que podrá interponerse en el acto de la notificación, si fuere personal, o dentro de los cinco días hábiles siguientes, y no necesitará ser fundado" (35). Como se recordará, el plazo para apelar, en la regulación anterior, era apenas de veinticuatro horas (36).

Tan importante pareció esta reforma a la Excma. Corte, que la menciona expresamente, en la parte considerativa del Auto Acordado de 1992, como un medio destinado a conferir a los agraviados "mayor amplitud y facilidad para la defensa de sus derechos conculcados" y la estima aconsejable, porque la aplicación del término "de este modo guarda correspondencia con el plazo que en la normativa general común se confiere para deducir este recurso".

En resumen, el № 6 del A.A., contiene una reforma y tres importantes especificaciones, a saber:

A. Amplia a cinco días hábiles el plazo de 24 horas que antes tenía el recurso de apelación.

B. Especifica que la sentencia definitiva de primer grado deberá notificarse tanto a quien hubiere deducido el recurso como a los recurridos que se hubieren hecho parte en él. 
C. Concede el recurso de apelación a estas mismas partes, quienes podrán también deducirlo en el acto de la notificación, si ésta fuere personal. Y

D. Puntualiza que el recurso de apelación no necesitará ser fundado.

Las reformas del plazo también ha venido a subsanar una situación caótica. Cuando el agraviado por la sentencia quedaba fuera del plazo para apelar, no siendo aquella susceptible de otro recurso jurisdiccional (37) recurría de queja.

Sin perjuicio de advertir la monstruosidad jurídica - no infrecuente, por cierto de utilizar un recurso de la vía disciplinaría, con fundamentos y fines jurisdiccionales, se daba en estos casos las curiosa anomalía de tramitar un recurso que sólo corresponde al agraviado por una actuación judicial, en circunstancias que resulta difícil concebir como agraviado a quien, al no deducir apelación en contra del fallo, se le debe considerar, más bien, conforme con lo resuelto (38).

Actualmente, en mérito de la reforma, el plazo base del recurso de queja y el de apelación, han quedado equiparados.

3.6.8. Tramitación de R. de P. en segunda instancia.- Otra reforma, a la cual la Excma. corte atribuye especial importancia y que, además, ha originado una interesante discusión académica (39), dice relación con el conocimiento del recurso de apelación.

Como se sabe, los tribunales colegiados resuelven los asuntos de que conocen, en cuenta o previa vista de la causa; y esta última forma de conocimiento supone - entre otros trámites - la colocación de la causa en tabla o su agregación extraordinaria a ella, la posibilidad de alegar y de suspender su vista.

En el sistema anterior, tanto en primera como en segunda instancia los R. de $\mathrm{P}$. se conocían y resolvían previa vista del recurso.

"El alto ingreso de causas de esta especie ... agregadas a las otras materias, que también deben figurar extraordinariamente en las Tablas de las diversas Salas de este Tribunal - señala la Excma. corte en el A.A. de 1992 - retarda su conocimiento y fallo, y produce al mismo tiempo postergación y demora la vista resolución de los demás recursos y causas de la tabla ordinaria".

De allí que la Excma. Corte haya resuelto simplificar la tramitación en segunda instancia mediante la regla general de que el recurso de apelación se conoce en cuenta preferente, que deberá darse a la Sala correspondiente "dentro de los cinco días de que sea ordenada" $(40)$.

Ello no obsta a que la Excma. Corte se haya reservado la facultad de decidir, a través de la Sala respectiva, (a) cuando la propia Sala lo estime conveniente o (b) cuan- 
do se le solicite con fundamento plausible, si ordena "traerlo en relación, para oír a los abogados de las partes": caso en el cual se agregará extraordinariamente la causa a la tabla respectiva de la misma Sala.

La nueva modalidad agiliza notablemente el conocimiento y fallo del recurso de apelación que, en el sistema anterior, a menudo tardaba meses en lograr su vista.

Es cierto que se ha eliminado el alegato del recurso, como regla general, y que ello constituye una desventaja para el fallo apelado. Pero ante la perspectiva cierta de la considerable tardanza en dilucidar asuntos que, por la naturaleza y cometido del R. de P., requieren de pronta resolución. El nuevo sistema subsana la coyuntura y deja a salvo la posibilidad del alegato si - la trascendencia o complejidad del asunto materia del recurso - la E. Corte lo estima conveniente o lo concede a la parte que se lo solicita con una justificación aceptable.

3.6.9. La condena en costas y su procedencia.- Es ésta, a mi juicio, una excelente innovación del A.A. de 1992; ya que, en ausencia de norma expresa y por una deformación generalizada del criterio para encarar las costas, éstas se consideran como un castigo o sanción y, por lo mismo, ningún tribunal se atrevía a condenar en costas en ausencia de norma expresa habilitante.

Por idéntica razón - que, obviamente, no compartimos - algunos han creído descubrir en la norma del № $11^{\circ}$ del A.A. - que faculta a las Cortes, "cuando lo estimen procedente", para "imponer la condenación en costas" - otro motivo de inconstitucionalidad del Auto Acordado, fundándose en que sólo se puede establecer una sanción por ley, lo que también resulta discutible.

Tengo para mí que la condena en costas no es sanción, pese a su nombre, como no lo es la condena al deudor a prestar lo que debe.

Las costas obedecen a un principio elemental de justicia retributiva. Obedecen al principio del justo resarcimiento. Al sujeto, titular de un derecho, que ha debido litigar para defenderlo o recuperarlo, no se le puede disminuir - como dice CHIOVENDA - el contenido patrimonial de su derecho, substrayendo de éste el costo de su defensa. Las costas compensan ese desmedro económico y su negación resarcitoria constituiría una injusticia.

Sea como fuere, por éstas no por mejores razones, la Excma. corte resolvió establecer la facultad de los tribunales para imponer la condenación en costas "cuando lo estimen procedente".

Esta última frase contiene un espacio demasiado abierto de discrecionalidad que, en un afinamiento futuro de esta normativa, sería conveniente acotar. 
Pero como la discrecionalidad no es sinónimo de arbitrariedad, sino la libertad de decidir con un criterio racional y justo lo que no se encuentra sometido a reglas expresas, creemos oportuno sugerir algunos criterios, atenidos al hilo conductor del principio resarcitorio.

Así, será procedente la condena en costas a favor del recurrente cuando, acogiéndose el Recurso aparezca claramente que la conculcación del derecho invocado, ha carecido de fundamento o justificación aceptable; cuando el acto agraviante sea manifiestamente contrario a derecho o irrazonable; cuando la omisión motivante del Recurso haya privado al recurrente de algún atributo del derecho protegido, y siempre, en segunda instancia, cuando en ella obtenga como apelante, la renovación o la modificación favorable del fallo denegatorio del primer grado.

Será procedente la condena en costas a favor del recurrido que se hizo parte, siempre que aparezca de manifiesto que el Recurso carecía de fundamento o justificación razonable; o resulte evidente que se ha pervertido la naturaleza y finalidad propias del Recurso, utilizándolo para otros fines, tales como obtener información reservada mediante el Informe de rigor y el requerimiento de "todos los antecedentes" que hace el tribunal, o para favorecer otras situaciones ventajosas para el recurrente o para terceros ajenos al recurso y, en fin, cuando el tribunal adquiera la convicción de que el Recurso se utilizó maliciosamente para amedrentar o inhibir o entorpecer la actuación legítima de una autoridad pública o de un particular, siempre que - en todos estos casos - el Recurso haya sido rechazado. Nos queda una razonable duda acerca de si procede la condena en costas en favor del recurrido que no se hace parte. Tal vez la duda provenga de la deformación profesional consistente en creer que las costas son carga de una parte en beneficio de la otra (41).

En cualquier caso, el № 11 del A.A. no distingue y, por lo tanto, no es lícito eliminar esa alternativa.

\section{LAS REFORMAS PENDIENTES}

Conforme al generalizado propósito de hacer más accesible y expedito el $\mathrm{R}$. de $\mathrm{P}$. y de conferir mayor amplitud y profundidad a la dignificación de la vida humana, que constituye la finalidad última del Recurso, cabría proponer numerosas reformas.

4.1. Unas - de iniciativa del constituyente - exceden el marco de este trabajo y sólo las dejaremos enunciadas con la siguientes preguntas: - ¿Cómo es concebible que en una sociedad humanista, que pretende asegurar a sus integrantes su mayor realización posible, se excluya del R. de P. al derecho a la educación en circunstancias que ésta - según la misma Constitución - "tiene por objeto el pleno desarrollo de la persona en las distintas etapas de su vida"? 
¿Puede la Constitución negar un recurso efectivo para proteger un derecho esencial e inseparable de la realización de la persona, que la propia Constitución alienta y declara como un deber del Estado?

Lo mismo podría decirse del derecho al trabajo y de la dignificación de la persona mediante su ejercicio, con respecto a un derecho que ni siquiera está contemplado en la Constitución, requisito previo para ampararlo con este Recurso.

He aquí, pues, dos tareas para el constituyente.

4.2. En el ámbito de las reformas al procedimiento del $R$. de $P$. pueden apuntarse como necesarias: a) el estudio del plazo del recurso, notoriamente breve y limitarse si consideramos que se trata de un plazo de prescripción extintiva de una acción que, al extinguirse, priva al derecho que el constituyente quiso proteger, de su mejor instrumento de protección; b) la limitación del plazo para informar. que a veces se prolonga mucho más allá del plazo del recurso; c) la radicación del recurso en el primer sorteo de Sala, a fin de evitar la elusión de su vista con trámites, a veces, innecesarios o reiterativos; d) la limitación de los trámites previos, que debieran ordenarse, en su totalidad, en una sola resolución y tener un plazo máximo de cumplimiento; e) similar limitación del plazo de las medidas para mejor resolver, de modo que se deba prescindir de ellas si no se cumplen oportunamente; f) la prohibición de paralizar o suspender la tramitaciones de un R. de P. por medidas dictadas en otros procedimientos; g) la reglamentación del desistimiento del recurso cuando el recurrido se haya hecho parte, y h) la modificación de la competencia relativa, materia a la cual pasamos a referirnos.

\subsection{Reforma del Tribunal competente}

A diferencia de lo que ocurre con el Recurso de Amparo, en que el tribunal competente para conocerlo es "la magistratura que señale la ley", no cabe duda que el R. de $P$. debe interponerse ante "la Corte de Apelaciones respectiva", lo que revela la trascendencia que el contribuyente quiso darle.

Ahora bien, en ambos Autos Acordados sobre el procedimiento del recurso, se señala como "Corte respectiva" a aquella "en cuya jurisdicción se hubiere cometido el acto o agravio al recurrente.

En otras palabras, bajo una óptica procesal contenciosa, se mira el Recurso como una demanda, al recurrido como un demandado y se sigue la regla general de la competencia relativa conforme a la cual es Juez competente para conocer de una demanda el del domicilio del demandado (42).

Pero el Recurso no es una demanda ni el recurrido es un demandado y hasta, eventualmente, puede no existir recurrido puesto que se trata de un procedimiento unilateral, como establecimos en su oportunidad. Cabría, entonces, hablar más bien de un 
interesado que requiere la intervención del juez en un asunto en que no existe contienda entre partes (43). Y, en tales circunstancias, sería oportuno recordar que en los asuntos no contenciosos es juez competente el del domicilio del interesado.

Con todo, no es la existencia o inexistencia de contienda lo que distingue esencialmente al $\mathrm{R}$. de $\mathrm{P}$. Este fue ideado y construido para brindar protección inmediata a una persona dañada en un derecho fundamental por un ilícito que desarticula el orden jurídico, el que se debe restablecer brindándole el debido resguardo al afectado.

Por lo que resulta evidente que el sujeto a quien el constituyente brinda protección es al titular del recurso y no al recurrido que es el que, eventualmente, ocasionaba el agravio.

Este recuento de características tan obvias del Recurso pudiera parecer superfluo; pero no lo es si se concede importancia a la determinación del tribunal competente.

En efecto, tratándose de un recurso procesal y ante la circunstancia de que el agraviado tenga su domicilio en un lugar que no corresponda a la jurisdicción de la Corte en la cual se infirió el agravio - acto u omisión arbitrario o ilegal - se brinda mejor protección al derecho conculcado y a su titular, otorgando competencia a la Corte del domicilio de éste que a la del lugar del agravio, que ordinariamente corresponde al domicilio del agraviante.

Y esa "mejor protección" consistirá (a) en el acceso más directo y expedito a la justicia, (b) en la "mayor amplitud y facilidad para la defensa de las garantías constitucionales que les fueron conculcadas" a los agraviados (44) y (c) en la disponibilidad del proceso que - más que a nadie - interesa al sujeto y destinatario de la protección.

No existe ninguna razón valedera, en un país de tan larga geografía como es Chile, para preferir el tribunal del lugar donde se produce el agravio al tribunal del domicilio del que lo sufre, en circunstancias de que el recurso se concede para proteger a éste.

Por lo demás, en una situación similar de protección preferente, el legislador no tuvo reparos - aun tratándose de un juicio contradictorio - para revertir la regla de la competencia relativa. En efecto, en la Ley sobre Abandono de Familia y Pago de Pensiones Alimenticias, es juez competente para conocer las demandas sobre alimentos deducidas por el cónyuge o por los hijos menores, el de la residencia del alimentario; es decir, del demandante (45).

La reforma de la competencia relativa del tribunal de primera instancia, además del principio de justicia procesal que lo anima, podría significar dos beneficios adicionales: a) terminaría con el pernicioso efecto del centralismo administrativo sobre la I. Corte de Santiago; y 
b) permitiría un reparto más equitativo y saludable del ingreso de recursos entre todas las Cortes del país.

Una de las causas de la saturación de R. de P. que afecta a la I. Corte de Santiago proveniente del hecho de que todos los Ministerios, Direcciones Generales de Servicios y la mayoría de los órganos de la Administración Central tienen su sedes dentro de la jurisdicción de esta Corte.

La reforma de la competencia no sólo repartiría los Recursos que reconocen origen en actos u omisiones de la Administración, conforme al domicilio de los afectados a lo largo del país, sino que, esta misma circunstancia, permitiría un progresivo conocimiento y expedición del resto de las Cortes en materias que, por obra de esta absurda centralización les priva del manejo y solución de los problemas contencioso administrativos cuyo volumen crece cada día y que la justicia ordinaria debe prepararse para abordar.

\section{CONCLUSIONES}

Cierto es que las conclusiones de un estudio debe extraerlas el lector. No obstante lo cual, a modo de resumen, formulamos las siguientes:

5.1. El R. de P. representa el mayor progreso de nuestra dogmática jurídica. Tiene valiosos precedentes en el Derecho público de México, Brasil y Argentina. Y nace como una extensión del Recurso de Amparo (Habeas Corpus) a otros derechos distintos de la libertad personal.

5.2. El mayor mérito del R. de P. consiste en dotar, con el más alto rango normativo, de tutela judicial superior, a los derechos y garantías que protege.

5.3. El R. de P. se caracteriza por su informalidad; su unilateralidad, su brevedad y concentración, su carácter inquisitorio, su amplitud protectiva y su provisoriedad.

5.4. La Reforma del Procedimiento del R. de P. se ha efectuado por Auto Acordado de la E. C. del 24-VI-1992, el cual suscita diversos repartos de inconstitucionalidad, que se deja enunciados. No obstante, dicho A.A. disfruta de una manifiesta legitimación fáctica, de una virtual inimpugnabilidad, y de innegables ventajas sobre el A.A. sustituido.

5.5. La motivación y los objetivos que la Reforma persigue, se encuentran contenidos en la parte considerativa del A.A., donde ambos se detallan.

5.6. Entre las innovaciones relevantes de la Reforma cabe señalar: - el cómputo del plazo para deducir el Recurso; - su examen de admisibilidad; - su agregación a la Tabla del día subsiguiente; - la perfiliación del recurrido como "parte" y sus dere- 
chos; - la ampliación del plazo para dictar sentencia; - la ampliación del plazo para apelar; - la simplificación del procedimiento en segunda instancia; y - la condena en costas y su procedencia.

5.7. Quedan importantes reformas pendientes a objeto de cumplir cabalmente las finalidades del recurso, en el centro de las cuales está la dignificación de la existencia humana.

5.8. Entre las que importan una reforma de la Constitución, destacan la incorporación del derecho a la educación a los derechos protegidos por el recurso y la instauración en la Constitución Política del derecho al trabajo y su dignidad, como paso previo a la necesidad de protegerlo en una sociedad humanista.

5.9. Entre las reformas procesales se señala un listado de ocho materias necesitadas de regulación para hacer el procedimientos más ágil y expedito.

5.10. Finalmente, se postula la reforma del tribunal competente, señalándose como tal el del domicilio del agraviado; lo que implicaría brindar a éste la protección procesal querida por el constituyente al facilitar su acceso a la justicia y a la disponibilidad del proceso, amén de otras ventajas distributivas dentro del Poder Judicial.

En resumen, tanta es la trascendencia y necesidad del $R$. de $P$., que si éste no hubiera sido incorporado a nuestro ordenamiento jurídico por el constituyente de 1976 y recogido por el de 1980 , tendría que haber sido creado por la jurisprudencia de nuestros tribunales, al menos, en la fase de retorno al Estado de Derecho. Hipótesis, ésta, que bien merece un estudio de factibilidad de tan justificado desiderátum.

\section{NOTAS:}

(1) El amparo mexicano, de espectro mucho más amplio y complejo que nuestros recursos de amparo y protección, está actualmente consagrado en los arts. 103 y 107 de la C. Pol. de 1971 .

(2) El "mandato de seguranca" está establecido en el art. $5^{\circ}$ numeral LXIX de la Constitución brasileña de 1988. El Habeas Corpus se regula en el numeral anterior del mismo artículo.

(3) El amparo argentino corresponde a nuestro R. de P.; y el Habeas Corpus del país hermano, a nuestro Recurso de Amparo.

(4) Néstor Pedro SAGUES: "La Ley Federal sobre Acción de Amparo en la República Argentina", Rev. de Ciencias Sociales, Edeval, Valpo., No 13, $2^{\circ}$ semestre, 1978.

(5) La acción del amparo contra actos de autoridad pública fue regulada por la Ley Federal № 16.986, del año 1966, y complementada por la Ley N¹7.454 que la extendió contra actos de particulares.

(6) Como se sabe, nuestro Primer R. de P. se estableció en el art. $2^{\circ}$ del A.C. No3 de 1976 (D.L. $\left.N^{2} 1.552\right)$. 
(7) Ver el No $2^{\circ}$ del Auto Acordado de 24 de junio/92, (D.O. del 27-VI-92) en adelante, el "el A.A, ".

(8) Ver Nos. $3^{\circ}, 5^{2}$ y $8^{2}$ del A.A.

(9) Ver el No 5 del Auto Acordado.

(10) Al respecto, ver R.D.J. t. LXXVI, 2a. p. secc. $4 a$. pgs. 332 y ss, Cons. $4^{2}$ y $5^{\circ}$. Ver también "Gaceta Jurídica", N67, pg. 30.

(11) En el R. de P. Rol 184-86 I.C. Valpso., en favor de un estudiante de la U. de Valparaíso previamente secuestrado y torturado, se pidió protección a su vida y seguridad, no pudiendo determinarse a los autores de los actos agraviantes. Esta unilateralidad manifiesta no fue obstáculo para tramitar el Recurso y obtener la protección solicitada.

(12) La necesaria condición de parte para ejercitar estas facultades procesales se desprende de los Nos. 4, 6 y 9 del A.A. Ver, también sentencia C.S. 4-VIII-1980, "Fallos del Mes" N²61-Pg. 235.

(13) Ver Nos. $1^{\circ}$ y $N^{\circ} 3^{\circ}$, frase inicial del A.A.

(14) Ver el $N^{\circ} 3^{\circ}$ del A.A.

(15) Ver Nos. $5^{\circ}$ y $8^{\circ} \operatorname{del} A . A$.

(16) Ver el N $10 \operatorname{del} A . A$.

(17) Ver el $N^{2} 7^{\circ} \operatorname{del} A \cdot A$.

(18) Ver No 3 inc. 2 y $N^{\circ} 7^{\circ} \mathrm{del} A . A$.

(19) Este mismo carácter le asignó el Prof. José Bernales Pereira en un Informe en Derecho solicitado por la 2a. Comisión Legislativa del Régimen Militar, Cit. por Sergio LIRA Herrera en su interesante obra "El Recurso de Protección", stgo., 1990, pg.136.

(20) Ver R. de P. Schacht y Cía. en R.D.J. t. LXXVIII, 2a p. Secc. 5a. pg. 126 y ss.

(21) No obstante, dando fe de que en Chile lo que más perdura son las soluciones provisorias, don Enrique PAILLAS Peña, en "El Recurso de Protección antes el Derecho Comparado", Ed. Jurídica, Stgo, 1990 pg. 89, a firma no conocer ningún caso en que, acogido un $R$. de $P$., se haya intentado de contrario un procedimiento ordinario para dejar sin efecto lo fallado por aquél.

(22) Ver Guillermo SCHIESSLER Quezada: "Algunas Cuestiones Relativas al R. de P.", en Rev. de Derecho de la Univ. católica de Valparaíso, Vol, VI, 1982 pgs. 353 y ss.

(22-bis) Ver nota 39

(23) Ver nuestra ponencia "Razón y Fuerza de la Constitución de 1980", en "Revista Chilena de Derecho" de la Pontificia U. Católica de Chile, Vol 16 - No2, (junio-agosto) 1989, pgs. 325 y ss.

(24) Para la motivación y objetivos, ver parte considerativa del A.A. de 1992.

(25) Asi ocurría en el R. de P. Hamel - fallo del 13-XII-1978- de la I.C. de Valparaíso. ver comentario de E. SOTO Kloss en "El Recurso de Protección", Ed. Jurídica, Stgo.,

1982 pg. 256. 
(26) Ver Cons, $4^{\circ}$ y $5^{\circ}$ del fallo I.C. de Concepción en R.P. Misael PINTO DEL 6-1-88 confirmado por la Excma. C.S. el 17-III-88, que contiene la siguiente doctrina: Como los actos administrativos producen efectos jurídicos de inmediato, el plazo para interponer el $R$. de $P$. empezó a correr el 20-XI86. (fecha del acto) aunque el recurrente haya tenido conocimiento de su dictación con mucha posterioridad (!). Ver transcripción del fallo en Pamela VERDUGO Johnston: "EI $R$. de $P$. en la Jurisprudencia", Ediar-Conosur, Stgo., 1988, pgs.128 y ss.

(27) Ver R. de P. Rojas Bascur, de la I. C. de Concepción - fallo del 31-X-80, confirmado por la C.S. el 15-XI-80 en R.D.J., T. LXXVII, 2a, p. S. 1a., pg. 109, y el comentario de E. SOTO K., op. cit., pg. 258.

(28) Ambos propósitos se manifiestan en el fallo del $R$. de P. Sucesión DUCCI Claro, I. C. de Valparaiso., del 26-XI-/), en que se accionó a raíz del movimiento de tierras en un predio de aquélla, por la Constructora Desco. El sentenciador señala que "es difícil fijar con exactitud el momento o fecha del acto privación, perturbación o amenaza, y se aviene más con la naturaleza de los hechos producidos concluir que el instante inicial, para el cómputo del término contemplado en el A.A., es AQUEL EN QUE LOS AFECTADOS HAN TOMADO CONOCIMIENTO DE ESOS HECHOS que no se consuman en un único instante y son claramente de tracto sucesivo". Añade el fallo que "El Tribunal deja constancia que prefiere en la especie, este alcance del término para recurrir de protección, PORQUE CONDUCE A QUE EL SISTEMA IDEADO POR EL CONSTITUYENTE TENGA REALES Y PRACTICOS EFECTOS". Ver comentario en E.SOTOK., op. cit., pg 257.

(29) No nos parece feliz la expresión "ACOGIDO", más propia de la estimación del fondo del asunto. Creemos más adecuado decir "Admitido", lo que - además - revela el cumplimiento de los requisitos de admisibilidad.

(30) La clara diferenciación entre "recurrido" y "parte" (recurrida) se desprende con claridad de los Nos. $4^{2}$ y $6^{\circ}$ del A.A.

(31) Ver el $N^{2} 4^{\circ} \operatorname{del} A . A$.

(32) En la posición correcta, ver s. C. Sup., "Fallos del Mes" №261, pg. 235, citado por Pamela VERDUGO, op cit. pg. 49.

(33) Nuevamente cabe señalar un impropiedad de la terminología jurídica que regía en la C. pol. de 1925, pero que, precisamente modernizó el A.C. N2 № 3 que el A.A. estaba implementando. En lugar de "garantias", la actual sistematización distingue entre "derechos" (facultades Subjetivas), "garantías" (medios establecidos para asegurar el respeto y la eficacia de los derechos) y "recursos procesales" (acciones que permiten requerir la intervención de la Justicia para tutelar los derechos y sus garantías). De alli la sistematización - ver epígrafes - de los Cap. I y II del A.C. No 3 y el lenguaje preciso"derechos y garantías" - del art. 20 de la C. Pol. vigente.

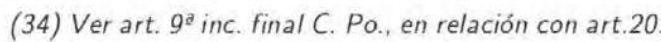

(35) $\operatorname{Ver} N^{\circ} 6^{\circ} \operatorname{del} A . A$.

(36) El plazo de horas resultaba difícil de determinar cuando la sentencia se notificaba por el Estado Diario. Y, como eran "horas corridas" esto obligaba a verificar a última hora del día Sábado, en la Secretaría de la Corte, si se había notificado el fallo. Innumerables apelaciones quedaron, así, fuera de plazo.

(37) Ver el No 9 del A.A. de 1977, reproducido por el No 12 del A.A. de 1992. 
(38) A pesar de lo dicho, se dio el caso de recursos de queja acogidos contra sentencias no apeladas. Ver fallo C.S. del 26-VI-86, Gaceta Jurídica Nº61, pg. 20; cit. por Pamela VERDUGO, op. cit., pg. 49.

(39) Ver el artículo de los Prof. Enrique Evans de la Cuadra y Eugenio Evans Espiñera "Constitución y Autos Acordados" en "El Mercurio de Santiago del 22-XI-93 y la contestación del Prof. Alejandro Silva Bascuñán en el mismo diario, del día 18-XII-93, bajo el mismo título.

(40) Ver $N^{\varrho} 7$ y parte considerativa - párrafo penúltimo - del A.A.

(41) Ver los arts. $138,141,142,144$ y 145 del C. de P.C.

(42) Ver el art. 134 del C.O.T.

(43) Ver el art. 817 del C. de P.C.

(44) Este objetivo figura entre los fundamentos del A.A. de 1992 de la Excma. Corte.

(45) Ver el art. $3^{\circ}$ de la Ley $N^{\circ} 14.908$. 